\title{
Evaluation of A Portable Brush-Cutter for Harvesting Sugarcane
}

\author{
David J. van Rest ${ }^{1}$
}

\section{INTRODUCTION}

The Secretary of Agriculture's recent report (1) ${ }^{2}$ shows that 92.6 percent of the farms growing sugarcane in Puerto Rico are of a total size of less than 50 cuerdas. ${ }^{3}$ These farms together in 1965 accounted for 23 percent of the sugarcane cuerdas. Most of these small farms are in hilly areas. Because of their small size and unfavorable terrain, fully mechanized operations are unlikely ever to be feasible.

To maintain maximum economic efficiency the cane is cut by the farmer himself, or an assistant under his immediate supervision. The question was raised whether a portable mechanical device could be used to increase the farmers' cutting rate in order to increase the area that he could cut in a season of approximately 100 days, without unduly increasing his costs. Even if the average costs of cutting were increased by a small amount, there would still be an economic advantage to the farmer if more cane could be cut in the season.

During the 1967 harvest an investigation was made into the usefulness of a portable motor-driven brush-cutter for this purpose.

\section{DESCRIPTION OF THE UNIT}

The unit tested (Figs. 1 to 3 ) was a Homelite $\mathrm{XL}$ brush-cutter made available by Dr. T. A. Hunter, New Products Manager of the Homelite Division of Textron, Inc. It is powered ( 3 ) by a single-cylinder 2-cycle engine. The drive shaft is engaged by a three-shoe double spring centrifugal clutch at 3,000 r.p.m. At the designed engine idle speed of 2,500 r.p.m. the clutch is not engaged, and the cutting blade is stationary. This facilitates starting. The drive-shaft runs down inside the main tube and connects to

${ }^{1}$ Associate Agricultural Engineer, Agricultural Experiment Station, Mayagüez Campus, University of Puerto Rico, Mayagüez, P.R. The assistance is gratefully acknowledged of Mr. Frank Delgado Font and Mr. Abel Blas Ortiz of Central Igualdad; and the encouragement and support of Dr. Jorge H. Rodriguez-Arias, Head, Agricultural Engineering Department.

Italic numbers in parentheses refer to Literature Cited, p. 347.

${ }^{3} \mathrm{~A}$ cuerda is equivalent to 0.9712 acres.

- The mention of this and other trade names does not constitute endorsement or recommendation by the Agricultural Experiment Station. They are used solely for the purpose of providing specific information. Neither is this report endorsed by Homelite. The recommendations made and opinions expressed are solely those of the author. 


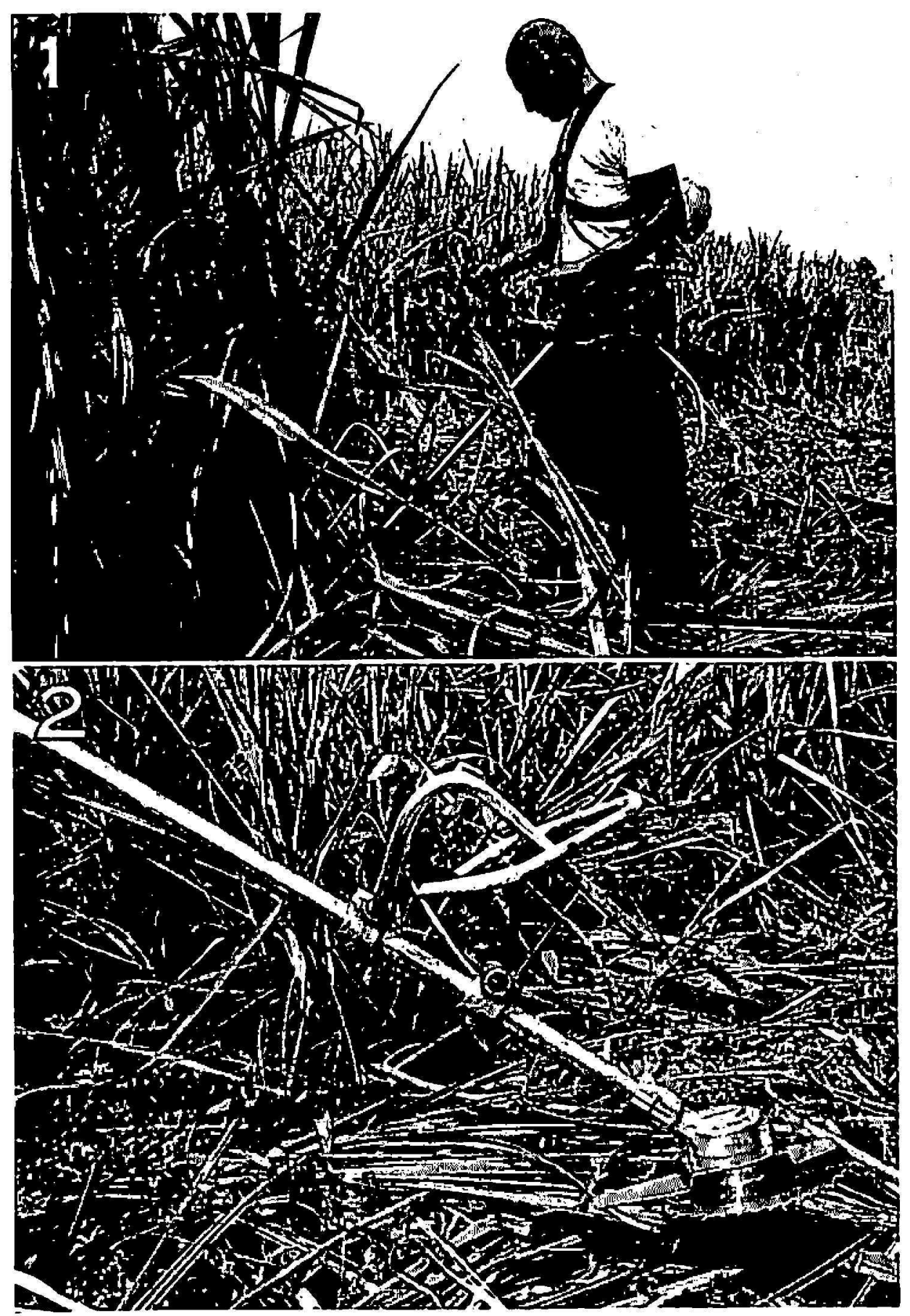

Fig. 1.-The unit under trial.

FIG. 2.-Close-up of the unit head showing the modified blade gutard and added front bumper.

the cutting-blade through beveled drive gears. A clamp at the point of balance transfers the weight through a snaphook to the operator's harness. The cutting-blade is angled to be parallel to the ground in the working position. The hindle bars are fitted with a spring throttle trigger that returns the engine to idle speed on release; they are adjustable for height, angle, and, independently, for inclination. The engine is equipped with a 
self-recoiling nylon rope starter, ignition cut-out switch, and choke. The cutting blade is a 10-inch circular saw blade. Assembled weight without fuel is 28 pounds. Fuel-tank capacity is 18 fluid ounces. The manufacturer

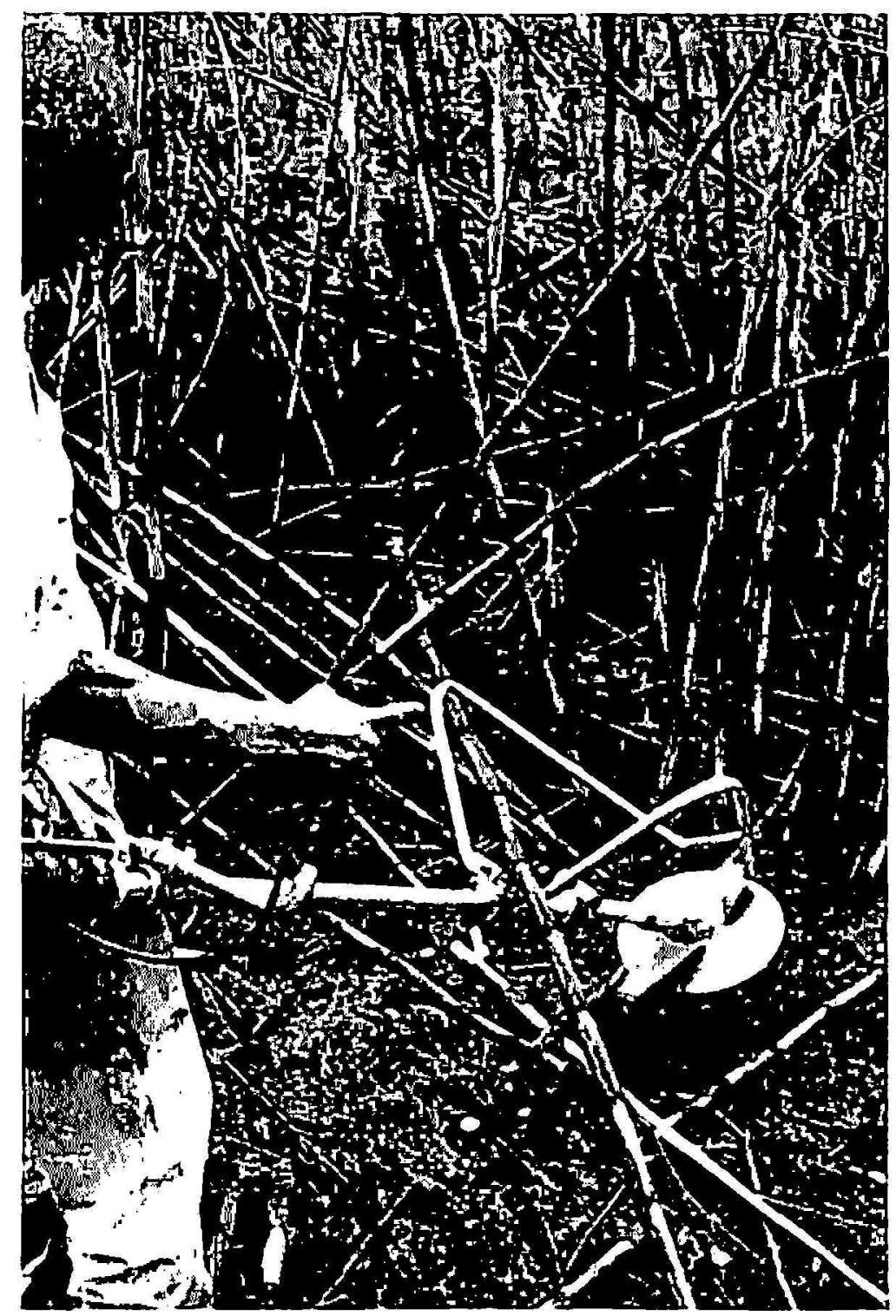

Fig. 3.-An unsuccessful attempt at windrowing by the use of diversion bars. Note the cane stalk that has tangled.

recommends a fuel mixture of 1 pint SAE 30 Motor Oil to 2 gallons of regular grade gasoline, that is, 1 in 17.

\section{DEVELOPMENT WORK}

A series of short field tests were made to develop the modifications necessary for the unit to work effectively in cane fields. The main problems confronted were:

1. The cut cane would fall in the direction in which it was inclined before cutting. This falling in random directions would interfere with further cut- 
ting and occasionally canes would strike the operator. It also made the canes difficult to collect by conventional methods.

2. Horizontal canes were extremely difficult to cut because it was necessary to incline the unit to move the blade out of a horizontal plane.

The first modification was a diversion bar to attempt to windrow the cane to one side. It was planned to cut only with one side of the blade in the expectation that the canes could be diverted away from the row towards one side only. However, it was found that a smoother cutting action could be achieved by "scything" back and forth at right angles to the direction of the row. This required the alternate use of the different sides of the blade.

The second modification therefore was a second diversion bar on the side of the unit to allow the cut canes to be diverted to either side out of the path of the operator. Different angles and heights were tried for the bars, but no one height served to divert all canes. Undiverted cane would topple between the bars and be caught. Hence a front bumper was installed as the third modification. This prevented all danger to the operator from falling cane and allowed cut cane to be pushed to the side in the course of the "scything action." A practical method of windrowing while cutting was not found.

Further problems were encountered with the blade assembly. Cut canes had a tendency to be drawn by the rotation of the blade into the space between the blade and the guard and to jam there. Also vines and trash were drawn into the space and tangled round the spindle head. Following correspondence on this point, the Homelite Division of Textron, Inc. supplied a modified guard which decreased the clearance from 15/16 inch to between $3 / 16$ and 5/16 inch, less than the diameter of the canes. There was noticeably less tangling and fewer difficulties with trash with the modified guard.

With the modifications the unit was found able to cut both burnt and unburnt fields of cane, provided the majority of the canes were reasonably erect. In a trial on land owned by La Plata Sugar Company where a large fraction of the cane was recumbent, cutting was not practical. The scything action swept underneath these horizontal canes. Moreover they fouled the the lower ends of the diversion bars obstructing forward movement. Cutting through the recumbent canes requires cutting with the blade at an angle to the horizontal and this was prohibitively awkward. To avoid the foulings the diversion bars were removed. It was found that the bumper bar alone was capable of all the diversion that could practically be achieved. With the exception of provision for cutting recumbent cane it was felt that a development plateau had been reached and that an assessment should be made.

\section{RESULTS}

\section{Unit Performance}

No mechanical problems were encountered in the trials. The engine idle speed was adjusted slightly on arrival. No other adjustments were made to 
the mechanisms. On two occasions difficulties were encountered in maintaining power. Both times the fuel in the tank had been almost exhausted immediately before. It was thought that dirt in the fuel was responsible. Flushing out the carburetor removed the difficulty in both cases. At one point the muffler worked loose and had to be tightened. Apart from cleaning and oiling the blade after use no servicing or maintenance was undertaken. Despite this the unit worked well whenever required. On no occasion did it fail to start, though repeated cranking was sometimes necessary.

\section{QUALITY OF WORK}

The blade cuts extremely close to the ground, harvesting more of the cane than is practical with a hand-cutter's knife or "machete." It should be noted that the base of the cane is the section richest in sugar, thus a higher yield or sugar per cuerda can be expected. Hand cutting often leaves a stump which has to be severed with a second cutting stroke to prevent interference with further work. The unit left no stumps. No attenpt was made to top or clean the canes, or to windrow them other than to divert them out of the way. The operator had no difficulty in doing this.

\section{Ease of HandLing}

The tests were of insufficient duration to assess operator fatigue. The modifications threw the unit slightly out of balance requiring more effort with the arms than would normally be expected. In spite of this, no operator discomfort was reported. Undoubtedly the noise, heat, weight, and vibrations would be stress factors. The operator does not handle the cane, thereby avoiding the cane hairs and poisonous vines and the possibility of accidentally cutting the grasping hand. He does not need to wear gloves. The cutting action does not require the operator to bend forward, as is necessary with a machete. Goggles were provided but not worn. In view of the lack of acceptance of a safety glove for hand-cutters, resistance can be expected to the use of goggles or high boots.

It was found possible, but not convenient for the operator to pick up and fasten the machine to himself. In the tests an assistant helped with this and also started and stopped the unit. The manufacturers state (4) that the unit is specifically designed for one-man operation, and the operator can start, operate, and shut down the unit at will. However, as with any power equipment, it is advisable to have somebody nearby in case of an accident.

\section{Fiend Assessment}

A field assessment was made on the morning of June 14, 1967 in a field of variety P.R. 980 on the lands of Central Igualdad. The cane had been planted in late October 1966, and was being cut for seed after 71/2 months 
growth. Lengths of row were marked off into 25 -foot sections. The time to cut this length was recorded; 4 sections were timed. On 2 of these sections the operator required help to unblock the unit. The time that he turned away from the row is not included in the cutting time. The other 2 sections were cut without stopping and lapsed time and cutting time were therefore equal. For these latter 2 sections the number of cane stalks and the gross weight of cut cane including leaves and tops, were recorded. The results are shown in table 1. Fuel consumption was measured. It was found that approximately 10 fluid ounces of gas and oil mixture were used in cutting sections 3 and 4, that is 50 feet of row. At this rate the fuel tank would need to be refilled at least every 11 minutes. For administrative reasons premium gas was used in this test. However, the manufacturer recommends regular gas and the cost assumptions are based on regular gas at 30 cents a gallon.

TABLE 1.-Field measurements

\begin{tabular}{c|c|c|c}
\hline \multirow{2}{*}{ Section No. } & \multirow{2}{*}{ Cutting time } & \multicolumn{2}{|c}{ Cane cut } \\
\cline { 3 - 4 } & & Stalks & Weight \\
\hline & Minstes & Number & Pounds \\
1 & 3.75 & - & - \\
2 & 2.95 & 71 & 104 \\
3 & 3.10 & 89 & 152 \\
4 & 3.10 & - & - \\
\hline Arerage of sections 2 and 3 & 3.02 & 80 & 128 \\
\hline
\end{tabular}

The measured rate of fuel consumption is considered rather high as it would require refueling every 11 minutes. The manufacturers suggest that it may have been caused by suboptimum adjustment of the carburetor. Their experience is that refueling should only be necessary every 15 minutes. In view of the approximate nature of the field measurements the cost calculations have been based on the manufacturer's estimated rate of fuel consumption.

In the absence of long-term tests or experience with the unit in the Tropics, a field effectiveness of 67 percent is assumed. This would allow for every 40 minutes of cutting, a further 20 minutes for refueling (3 times), coping with difficulties such as jamming and tangling, and resting and refreshing the operator. The effective cutting rate has been calculated on this basis, as 0.72 tons per hour.

Hand cutters in the same field on the same day cut 92 tons in 168 manhours, an average of 0.55 tons per hour. These figures were supplied by courtesy of the Section Manager. 
To estimate the likely usefulness of the unit, assumptions will have to be made about the system that goes with it. For a fair comparison, provision has to be made for trimming and topping and the added difficulty of collecting the unordered canes. For simplicity, this is assumed to add 33 percent to the collecting and bundling time, that is, half an hour per ton of cane cut. The economic consequences of not trimming or neither trimming nor topping have not been considered. On this basis the hours of work per ton of cane cut and windrowed are:

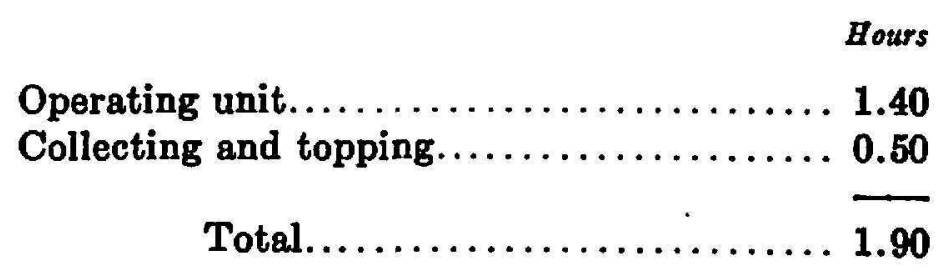

For hand cutting the total was 1.82 hours.

From the figures of table 1 the gross weight of cane per cuerda was calculated as 43,000 pounds. Assuming 15 percent trash and tops, the net weight of cane was 36,500 pounds per cuerda.

\section{Cost Estimates}

\section{Initial investment}

Dollars

Cost of unit...................................... $\quad 250$

Cost of proposed modifications for use with cane $\ldots \ldots \ldots \ldots \ldots \ldots \ldots . . . \ldots \ldots$

Cost of fuel can and strainer................................ 4

Total..................................... $\overline{279}$

The life of the unit is estimated at 1,200 hours of cutting. This requires a complete overhaul after the first and second seasons and discarding the unit after the third season. The unit is assumed to be used 6 hours a day ( 4 hours of actually cutting) for 100 days per season.

Thus the initial investment is spread over 1,300 tons of cane.

Machine costs per ton

Cents

Initial investment. ................................ 21

Repairs, parts and servicing

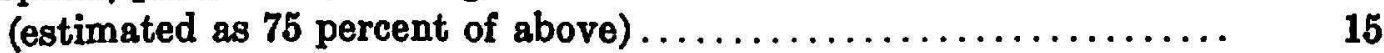

Fuel ( $1 / 2$ gallon of mixture)

Regular gas at 30 cents per gallon...................... 14

2-stroke motor oil at $\$ 2.16$ per gallon $\ldots \ldots \ldots \ldots \ldots \ldots \ldots \ldots \ldots \ldots$

Total...................................... 56 
Labor costs per ton

Cents

Operator wages at $\$ 1.00$ per hour............................ 140

Collecting and topping at $\$ 1.00$ per hour.................... 50

Total.................................... 190

Total cutting costs per ton

With the unit.

2.46

Hand cutting.

1.82

\section{DISCUSSION}

\section{The Implications}

The time saved from a higher rate of cutting is almost exactly equal to the extra time required for windrowing and topping. Although there is no net saving of time, there is an extra total machine cost of 56 cents per ton. Hence an economic case can not be made for the use of the unit at this stage. However, now that a feasible method has been demonstrated, the requirements can be stated more specifically. These also have a wider significance since in many respects the problems here encountered are the same for the whole mountainous area. Power is needed on unfavorable terrain. A portable light gasoline engine does not seem to be the answer. The high speeds required to produce power in a light unit demand sophisticated engineering features and competent servicing. In these circumstances this represents "advanced technology" with all its characteristic disadvantages. Despite the years of experience and training needed to produce a good hand-cutter and the great difference in out-put between a good and a poor worker, in a modern society this is considered unskilled work. Use of a machine becomes semi-skilled work. In the area where the units might be used the required competences are scarce. Hence the requirements for servicing would be classed as high skills. Moreover, if the more complicated servicing tasks were undertaken elsewhere (for example, major overhauls in the centrals' workshop) and intensive instruction were provided, not all the farmers could be expected to absorb these skills. It should be noted that, if they did absorb these skills, they would then be eligible for other more highly paid employment. The operators would also have to be trained in proper safety procedures both for the unit and for the fuels. The enormous amount of combustible material in the cane fields at certain times and the large potential losses from fire make the presence of gasoline in a field a considerable risk, and re- 
quire a responsible attitude from the operator. This will severely limit the number of potential operators.

The productivity analysis underscores the importance of the collecting component of the cane harvest. In a typical hand-cutting system, gathering and forming bundles requires as many man-hours per ton as the operation of cutting, cleaning, and windrowing. It would appear that opportunity for improving the efficiency of the harvesting system will depend on new means for collecting. In these trials the unit under study cut 31 percent faster than a hand cutter, but this benefit was lost because of the requirements of the gathering method. Were a new method of collecting to be developed it is possible that this potential benefit could be realized.

\section{REQUTREMENTS FOR OPERATOR SKILL}

In view of the significance of the "skill" factor the unit's requirements were examined in detail. The Owner's manual (2) called for an overhaul after every $\mathbf{5 0}$ hours of operation. Following correspondence on this point the manufacturers state (4) that this frequency is specified for duties such as cutting heavy, woody structure where there are severe shock loads on the driving members. For cutting cane the interval could be increased to every 200 hours. In practice this would be once in midseason with a major overhaul between seasons. As it involves pulling and repacking bearings and checking and replacing gaskets this is considered "off-farm" servicing that would have to be organized on an area basis, as would the major overhaul.

The operator's job specifications would then be:

1. Wear adequate protective clothing. This should include high top shoes or boots to protect the ankles and shins, and goggles to protect the eyes.

2. Check air-filter daily, and clean when clogged.

3. Prepare the fuel. It should be mixed thoroughly in a safety container, in the exact proportions given in the fuel mixing table.

4. Refuel. The engine must always be shut off before refueling. Move at least 10 feet away from refueling spot before restarting the engine.

5. Fuel should be carefully strained through a cloth as it is poured into the tank. This is not mentioned in the manual but is recommended in view of the field experience during the trials.

6. Keep the blade sharp. It must be sharpened carefully to avoid unbalance which would cause damaging vibrations. It is recommended that a spare blade be purchased and that they be alternately rounded, gummed, sharpened, and set by an experienced saw shop.

7. Wipe equipment down after use. Check all fastening parts and clamps, tightening any screws or nuts which have worked loose. Remove pitch and juices with turpentine and a rag, or soak blade in warm water and detergent. Dry blade thoroughly and apply rust preventative immediately. 


\section{SUMMARY}

It was found possible to modify a power-driven brush-cutter to cut, but not to windrow, standing cane. A short trial was made on cane being cut for seed to assess the usefulness and estimate the costs of operation in comparison to hand-cutting. The benefit from a faster rate of cutting did not compensate for the extra hand labor required for the operations of collecting, cleaning and topping. New procedures will have to be developed for these operations if the potential benefit from the use is to be realized.

The advantages and disadvantages of the unit are described and the implications for operator selection and training and the provisions for servicing, are outlined.

\section{RESUMEN}

Fue posible modificar un cortador de malezas motorizado para cortar la caña de azúcar, pero no se pudieron amontonar los tallos cortados en hileras. Se hizo una pequeña prueba con caña para semilla, a fin de evaluar la utilidad del cortador de malezas y estimar el costo de su funcionamiento comparado con el costo del corte a mano. Las ventajas de un corte más rápido no igualaron la mano de obra adicional que requerían las operaciones de recoger, limpiar y descocollar las cañas cortadas. Será necesario desarrollar nuevos procedimientos para estas operaciones, si es que ha de sacársele un mejor provecho al cortador de malezas modificado.

También se describen las ventajas y desventajas de dicha unidad; las consideraciones que hay que tener en cuenta al escoger y adiestrar al operario y las precauciones necesarias para su mantenimiento.

\section{LITERATURE CITED}

1. Hernández Agosto, M., 'La Agricultura de Puerto Rico-Situación y Posibilidades", Informe al Gobernador, September 1966.

2. Homelite Division, Textron Inc., Model XL, Brush-cutter Owner's Manual, YC 7-64, Revised January 1966.

3. Homelite Division, Textron Inc., XL Brush-cutter Specifications, B-316.

4. Hunter, T. A., Personal communication, 1967. 